\title{
0 Fórum Nacional de Cursos de Geologia e as Diretrizes Curriculares Nacionais: histórico e perspectivas
}

\author{
Celso Dal Ré Carneiro \\ Instituto de Geociências, Universidade \\ Estadual de Campinas, Campinas, SP. \\ cedrec@ige unicamp.br
}

\begin{abstract}
The National Forum of Geology Courses and the National CuRriculum GuideliNES: HISTORY AND PERSPECTIVES. Professional training in Geology is intended to supply activities that can be viewed as typically linked to the State. Therefore, clear rules are essential for the operation of undergraduate courses in Geology and Geological Engineering, as the National Curriculum Guidelines (NCGs) approved 2012 by the "Conselho Nacional de Educação" (CNE). The decision is mainly based on documents from the National Forum of Geology Courses (NFGC). Community expectations were probably met, because concerns and expectations of teachers, professionals and students have been considered. This article for the event "Interfaces of Geosciences and Education: 40 years of experience (1973-2013)" aims to review the decisive role of FNCG. The role played by the Forum can be partially explained by an expansion and sharing of concerns among the Forum components. The orientation given by NCGs may inspire restructuring of curricula, new configurations and changes in course design. Innovative teaching projects, with emphasis on fieldwork as an essential training tool for geologists, associated to laboratory studies and intensive bibliographic activities, can replace ancient rigid and detailed models of curricula and specification of classroom hours. A consequence will be an improvement of the interaction with professional regulatory bodies, and more effective guidelines for a periodical evaluation of the courses. Citation:Carneiro C.D.R. 2014. Fórum Nacional de Cursos de Geologia (FNCG) .Terræ Didatica, 10(3):191-203. http://www.ige.unicamp.br/terraedidatica/.
\end{abstract}

KEYWORDS : Curriculum Guidelines, curricula, higher education, Geology, Geological Engineering, university, professional regulation, pedagogical project.

RESUMO A formação profissional na área de Geologia destina-se a suprir um campo de atividades tipicamente ligadas ao Estado. Esse fato acentua a importância de regras claras para funcionamento dos cursos de graduação em Geologia e Engenharia Geologica, representadas pelas Diretrizes Curriculares (DCNs), aprovadas pelo Conselho Nacional de Educação (CNE) em 2012. A decisão aproveita grandemente as proposições do Fórum Nacional de Cursos de Geologia (FNCG) e atende às preocupações e anseios de docentes, profissionais e estudantes. Este artigo do evento "Interfaces Geociências e Ensino: 40 anos de experiências (1973-2013)” examina, em perspectiva, a contribuição para as DCNs de um grupo de professores e alunos voltado para renovação no ensino superior de Geologia formado na USP em 1973. As DCNs mantêm várias recomendações relevantes da orientação precedente - o Currículo Mínimo -, e introduzem orientações para reconfigurar cursos, reestruturar currículos e mudar concepções. A ênfase ao trabalho de campo como ferramenta imprescindivel de formação de geólogos, associada ao laboratório e intensivo estudo bibliográfico, pode levar a projetos pedagógicos inovadores, em substituição a rígidos modelos de currículos e cargas horárias. Além da consequência esperada - profissionais mais bem preparados - haverá melhor interação com órgãos de regulação profissional (sistema CREA-CONFEA), e orientações mais eficazes para a avaliação periódica dos cursos.

PALAVRAS-CHAVES: Currículo Mínimo, Educação Superior, Engenharia Geológica, universidade, regulamentação profissional, projeto pedagógico, mudança curricular. 


\section{Introdução}

As Diretrizes Curriculares Nacionais (DCNs) são um mecanismo que vem sendo adotado pelo Ministério da Educação (MEC) para orientar a concepção geral, implantação e avaliação dos cursos brasileiros de graduação das várias áreas do conhecimento, visando atender aos dispositivos da Lei de Diretrizes e Bases da Educação Nacional (LDB). A Lei (Brasil 1996) fundamenta o processo de formação na educação superior, por intermédio de: (a) desenvolvimento de competências e habilidades; (b) aperfeiçoamento cultural, técnico e científico do cidadão; (c) flexibilização dos currículos; (d) implementação de projetos pedagógicos inovadores para a formação profissional, vinculados a uma expectativa de mudança.

O Fórum Nacional de Cursos de Geologia (FNCG) é composto por coordenadores de cursos, dirigentes das unidades universitárias que ministram tais cursos, bem como docentes, profissionais, entidades estudantis, entidades profissionais e órgãos de governo envolvidos com a formação de geólogos no Brasil. O surgimento do FNCG decorreu, como veremos, do debate iniciado nos anos 2000 a respeito das Diretrizes Curriculares para os Cursos de Graduação em Geologia e Engenharia Geológica.

Azevedo e Terra (2008) apontam que, com o processo de industrialização do País iniciado com Getúlio Vargas e impulsionado nos anos 1940 e 1950 pela criação de grandes empresas estatais como a Petrobras, a formação de geólogos tornou-se questão de Estado. Assinalam que o processo gradual de criação de cursos superiores de Geologia experimentou hiato de aproximadamente 80 anos, desde que em 1876 foi criado, com disciplinas específicas, o curso pioneiro de Engenharia de Minas, da Escola de Minas de Ouro Preto. Nos anos 1950, novos cursos foram instalados em universidades e desde então formaram-se alguns milhares de geólogos. Uma das preocupações centrais fora atender ao "desafio histórico delegado pela sociedade brasileira à Petrobras: encontrar petróleo no Brasil e ser um agente do desenvolvimento nacional" (Azevedo e Terra 2008, p.381).

Até fins dos anos 1990, os cursos deviam obedecer a um modelo de "Currículo Mínimo", que havia sido definido na década anterior, sob ativa e dinâmica participação da comunidade nacional de Geologia, representada pelas sociedades científicas, com destaque para a Sociedade Brasileira de Geo- logia, profissionais em exercício, alunos e docentes de universidades.

A formulação de Diretrizes Curriculares para esse conjunto de cursos de graduação experimentou atraso em relação a outras áreas, cujas propostas de DCNs foram aprovadas ao longo dos anos 2000. No caso da área de Geologia, o debate estendeu-se até 2012, quando o Conselho Nacional de Educação aprovou por unanimidade o Relatório do Prof. Dr. Luiz Roberto Liza Curi (Curi 2012), que define as DCNs desses cursos (Brasil 2012). No documento, o relator propõe superar os "modelos de currículos que encerram elevado grau de detalhamento de disciplinas e cargas horárias e impedem que sejam implementados e transformados projetos pedagógicos mais inovadores pelas Instituições de Educação Superior (IES)" (Curi 2012, p.1). Com a sistemática das DCNs, houve transformação radical tanto na criação de novos cursos quanto nos mecanismos de avaliação de cursos existentes. A reorientação faz emergir novas configurações, que apontam para a necessidade de se reestruturar os currículos e a concepção geral dos cursos de graduação.

Sob a perspectiva de que qualquer mudança curricular só terá significado se contar "com a participação da maior parcela possível da comunidade interessada" (SBG 1982), o presente artigo apresenta um breve histórico de iniciativas da comunidade nacional de Geociências no sentido de interferir positivamente e colaborar para que as novas DCNs incorporassem preocupações e anseios de docentes, profissionais e estudantes desse campo do conhecimento. O texto busca atender ainda a dois objetivos: (a) descrever a contribuição dada pelo Fórum Nacional de Cursos de Geologia (FNCG) para aprimorar, por meio das DCNs, tanto a qualificação como a formulação de estratégias gerais para formação de geólogos e engenheiros geólogos no Brasil, e (b) analisar, em comparação com o sistema anterior, relativamente mais rígido, de currículo mínimo, algumas proposições que foram preservadas, ao lado de potenciais mudanças e inovações, apoiadas no mecanismo das diretrizes, que podem surgir na formação em Geologia e Engenharia Geológica.

Buscaremos situar as atividades empreendidas desde 2002 pelo FNCG como uma espécie de continuidade, porém em outro nível estratégico, das iniciativas de modificação curricular introduzidas pelo então chamado Grupo de Ensino de Geologia e que foram expostas por Amaral $(2013,2014)$, 
Negrão $(2013,2014)$ e Cunha $(2013,2014)$ no evento "Interfaces Geociências e Ensino: 40 anos de experiências (1973-2013)", realizado na Universidade Estadual de Campinas, em 2013. Para recompor os antecedentes das Diretrizes Curriculares Nacionais de Geologia Engenharia Geológica (DCNGEG) propomo-nos a fazer pequena análise das características especiais que diferenciam esta profissão de outras, para depois examinar o processo de formulação do currículo mínimo dos cursos, que contou com ativa participação de um conjunto de geólogos e estudantes (Cunha 2013, 2014), com apoio do Grupo de Ensino de Geologia.

\section{Uma profissão singular}

"Só podemos imaginar a profunda alteração da nossa economia se os economistas forem apresentados ao tempo geológico como algo natural" (Cervato e Frodeman 2012)

A Geologia tem como característica essencial a visão do presente, passado e futuro acoplada a uma perspectiva holística do processo histórico-geológico (Potapova 1968, 2008). Não é possível descrever a realidade atual do planeta em termos de "uma Geologia física separada de uma história" (ver, por exemplo, Simpson 1963), tal como havia sido percebido no século XVII por Renée Descartes; “os objetos físicos estão inscritos na gênese do mundo e a evolução não tem como ser estabelecida sem os objetos físicos que o constituem" (Menegat 2008, p.437). Uma consequência da abordagem integradora é a alteração da terminologia, delimitação e métodos da Geologia, ciência que se expandiu até tornar-se importante alicerce das Geociências, também conhecidas como Ciências da Terra (Anguita 1996, Peter e Hodder 1997).

As atividades profissionais do geólogo e a pesquisa geocientífica em vários campos do conhecimento têm sido revolucionadas pelo avanço tecnológico em observação e monitoramento do planeta por meio de satélites orbitais, sistemas terrestres, representações tridimensionais, sistemas de informações georreferenciadas (GIS), sistemas de cadastro de dados de superfície e subsuperfície e softwares de visualização e modelagem. As bases de dados assim geradas possibilitam compreender os processos que hoje dominam a Terra e que controlam sua evolução desde o passado remoto. O complexo arranjo de sistemas dinâmicos sob o qual o planeta opera e evolui sofre efeitos dos processos antrópicos (Hooke 2000); todos eles, naturais e antrópicos, têm sido monitorados em tempo real. A compreensão dos fenômenos não lineares e das retroalimentações que dominam o sistema (Pitman 2005) ajuda a identificar implicações das mudanças para a sustentabilidade global e regional (Leemans et al. 2009). Na exata medida em que a interpretação de múltiplos dados estimula o aparecimento de vastas redes de pesquisa cooperativa nacional e internacional, melhorou a compreensão das interações que ocorrem tanto no interior de cada esfera, como entre duas ou mais esferas materiais.

Os estudantes passam a saber melhor como preservar o meio que os cerca, ao mesmo tempo em que melhoram a qualidade, a profundidade e a abrangência de sua compreensão geral sobre os processos que ocorrem no ambiente (Orion 2001, p.97). Enfraqueceu-se nos estudos da Terra uma orientação meramente exploratória, utilitarista, e assumiu-se nova dimensão, de respeito ao planeta, bem exposta na frase do Prof. Dr. E.V. Barroso, em 2008, ao enviar convite a ex-alunos e à comunidade nacional, para participar da comemoração dos 50 anos do curso de graduação em Geologia da UFRJ: "mais de mil geólogos por aqui passaram, acalentando sonhos e dedicando-se a compreender a Terra, para trabalhá-la e respeitá-la” (Barroso 2008). Tal cenário aumenta, em lugar de diminuir, a atratividade da profissão, exposta dessa forma pelo maior expoente da geologia brasileira, Prof. Dr. Fernando Flávio Marques de Almeida [1916-2013]:

Felicito-os pela escolha dessa bela profissão. Ela lhes dará oportunidade de ajudar a decifrar a Terra, usufruir os encantos da vida ao ar livre e satisfazer o espírito de aventura que existe em todos nós. Como eu, correrão o risco de morrerem de sede perdidos nas dunas escaldantes do deserto do Saara, beberão água do radiador de caminhão quebrado no Chaco Boliviano, subirão à borda da cratera do vulcão em erupção El Fuego na Guatemala, verão os gêiseres expelindo água fervendo perto de Raratoa na Nova Zelândia e quase morrerão de frio nos planaltos cristalinos da península de Kola a norte do Circulo Polar Ártico. Com minha vivência de 66 anos de geologia posso lhes garantir ser essa a mais prazerosa das profissões e digna de ser vivida (Almeida 2004).

O Professor ajuda-nos a valorizar a difícil missão prática de formar geólogos para o mundo 
atual, ao relatar a beleza e os desafios permanentes da profissão abraçada por geólogos e engenheiros geólogos e salientar, no texto, que a motivação da Geologia vai além da mera curiosidade científica.

\section{Grupo de ensino de geologia/geociências}

O Grupo de Ensino de Geociências surgiu na USP, no início da década de 1970, tendo envolvido professores e estudantes. Em 1978 o grupo desligou-se daquela universidade e, ao buscar modos de se recompor, deu origem ao Grupo de Ensino de Geologia, cujos objetivos envolviam contribuir para a introdução de mudanças no ensino superior de Geologia no Brasil. Na primeira reunião do grupo, em meados de 1979, estabeleceram-se duas categorias de objetivos (GEG 1979):

1) objetivos a médio prazo: (a) promover a reaglutinação física do grupo; (b) atuar no âmbito do ensino superior de Geologia; (c) obter o reconhecimento e a valorização do grupo na comunidade geológica.

2) objetivos a curto prazo: realizar tarefas prementes, tais como a finalização de dissertações e teses, e oferecer um Curso de Especialização em Ensino de Geociências em Belém, PA, junto à UFPA, além de manter vivas as alternativas de ação abertas pelo grupo, como a presença ativa junto à Comissão de Ensino da Sociedade Brasileira de Geologia (SBG, cuja sigla passou a ser, mais recentemente, SBGeo, para distinguila da Sociedade Brasileira de Genética) e a realização de cursos periódicos de planejamento de ensino.

A reaglutinação física somente aconteceria a partir de 1983, na Unicamp, com a criação da Área de Educação Aplicada às Geociências no Instituto de Geociências, que se tornou o embrião do Departamento de Geociências Aplicadas ao Ensino, criado em 1997, mas que deve ser extinto em 2014, devido a insuficiente número de docentes.

Naquela época - início dos anos 1980 - o Centro de Geologia Eschwege era objeto de movimentos ordenados no sentido de ser institucionalizado por meio de vinculação à Universidade Federal de Minas Gerais (UFMG). O tema despertava, portanto, menor preocupação da comunidade nacional do que a necessidade de propostas de mudança curricular, reconhecida pelo Ministério da Educação (MEC).

Coube à Comissão de Ensino da SBGeo pro- mover uma série de consultas e pesquisas que culminaram na elaboração de proposta de Currículo Mínimo para os cursos de graduação de Geologia e em Engenharia Geológica (SBGeo 1982). A cooperação ativa entre o MEC e a SBGeo culminou na elaboração do documento de síntese $A$ formação do geólogo nas universidades brasileiras: um retrato de duas décadas (SBGeo 1984). Os dados e informações recolhidos na pesquisa oferecem um quadro bastante detalhado da realidade do ensino que vinha sendo praticado nas escolas e das necessidades e desafios encontrados no campo profissional. Desde então, jamais tornou a ser conduzido no País um levantamento de mesma envergadura e objetivos.

O Grupo de Ensino de Geologia organizou-se de modo a apoiar ativamente o levantamento de dados sobre a realidade de cada um dos cursos existentes na época, fomentar a realização de simpósios de ensino com caráter deliberativo - aspecto até certo ponto polêmico na comunidade - e, ao final, estabelecer um conjunto de regras para os cursos que garantissem adequado funcionamento. Pode-se afirmar que as iniciativas do GEG contribuíram para a construção da base legal do currículo mínimo dos cursos.

\section{Contexto político e econômico}

Em contraste com o incentivo dado à "profissão do futuro", nos anos 1950 e 1960, pela contribuição ao desenvolvimento, via petróleo e firmes investimentos em mineração, na década de 1990 ocorreu alto nível de desemprego no País, em parte motivado pela crise econômica que se estendeu desde o final da década de 1980 até meados dos anos 1990. No período foram inúmeras as dificuldades dos cursos de Geologia, como reflexo do fato de que o contexto político e econômico influencia diretamente a empregabilidade de geólogos.

Assine (1994) aplica a expressão "extinção em massa de geólogos" para descrever o fenômeno que se acentuou entre meados da década de 1980 e o início do século XXI. Diversos fatores, combinados, podem gerar um quadro desfavorável à absorção de geólogos pelo mercado de trabalho; o cenário, por sua vez, impactou decisivamente os cursos de formação de geólogos e engenheiros geólogos. Até mesmo decisões políticas podem ter causado desemprego; para muitos, a promulgação da Constituição (1988) é exemplar, devido ao impedimento de que empresas de capital estrangeiro investissem em pesquisa mineral, o que contribuiu para o cená- 


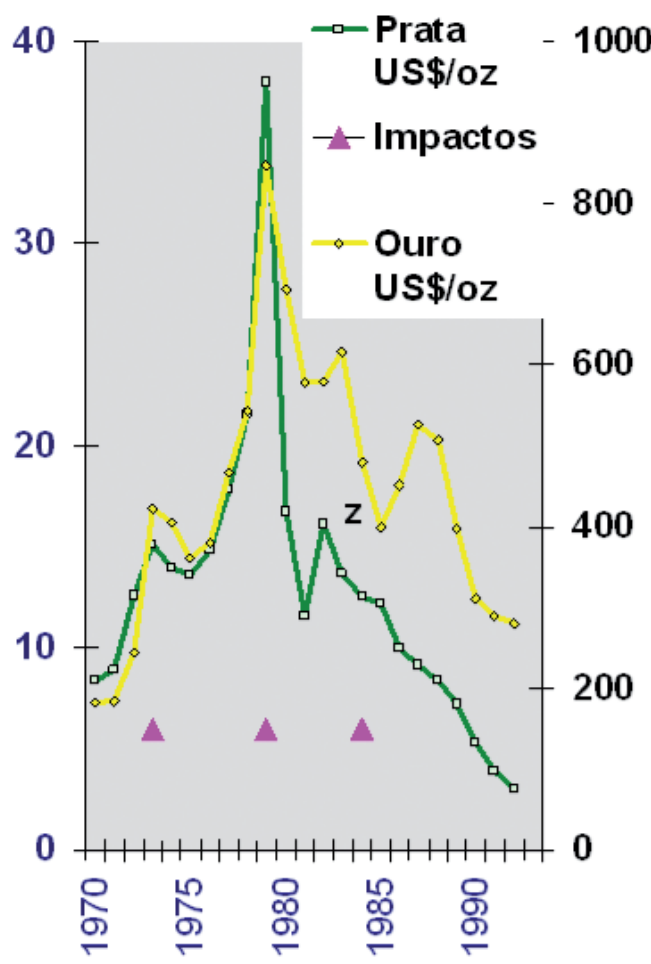

Figura 1. Eventos de "extinção em massa de geólogos", correlacionados a oscilações de preços de metais preciosos, no período entre 1970 e meados da década de 1990 (Fonte: Assine 1994)

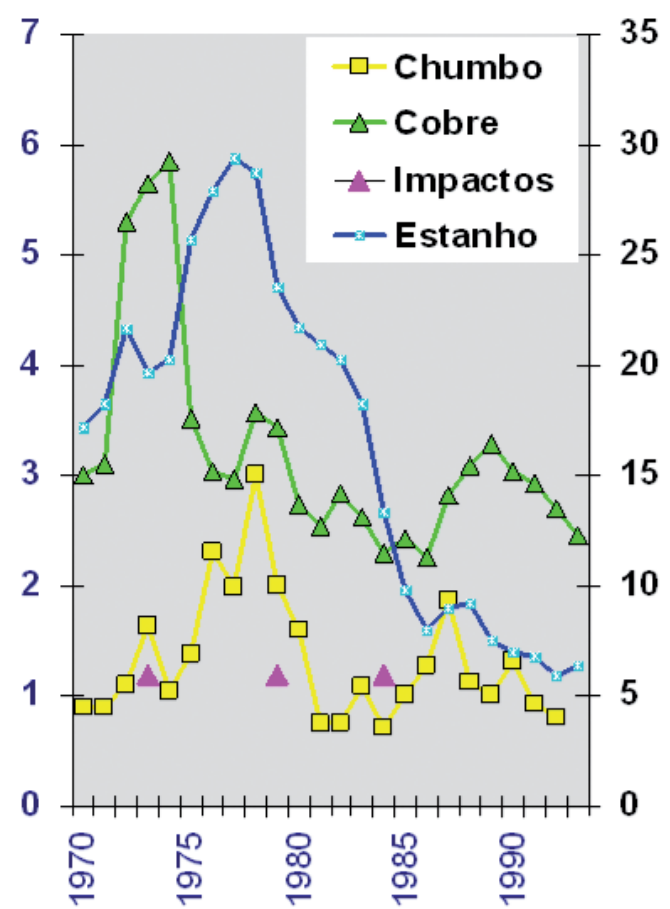

Figura 2. Eventos de "extinção em massa de geólogos", correlacionados a oscilações de preços de chumbo, cobre e estanho, no período entre 1970 e meados da década de 1990 (Fonte: Assine 1994) rio de desemprego então vivenciado.

A comparação dos gráficos das figuras 1 a 4 é ilustrativa, ainda que a interpretação dos dados não seja simples e possa ultrapassar o escopo do presente estudo: os dois primeiros diagramas foram obtidos de Assine (1994); sugerem que o descompasso entre preços de metais valiosos amplamente utilizados na indústria tenha reflexos quase imediatos na quantidade de empregos disponíveis para geólogos. Nos anos 1990, a etapa mais crítica e desfavorável dos cursos de Geologia (e Geofísica) coincide com quedas de preços e, portanto, redução da procura, de bens utilizados na indústria e commodities essenciais no mundo moderno. A oscilação de preços de commodities como o petróleo também parece exercer influência importante, uma vez que a remuneração salarial, de certa forma, acompanha a tendência de sobe-e-desce.

O gráfico da figura 3 mostra a oscilação dos preços de ouro desde 1969. É notável que os dois amplos picos no gráfico coincidam com o aumento da procura por cursos de Geologia no Brasil.

A figura 4 sugere que, quando o desemprego aumenta, diminui a procura pelos cursos da área; além disso, muitos estudantes que enfrentavam dificuldades nos respectivos cursos de graduação preferem abandonar a carreira; isso diminui o número de formados, conforme apontado por Janasi (2012). Vivencia-se hoje uma situação similar de "pico" de preços, que coincide com aumento da procura e da oferta de vagas desses cursos. Quanto tempo durará esta fase? Ninguém é capaz de fazer previsões seguras.

Na transição dos anos 2000 até a década atual houve criação de novos cursos e consequente aumento de vagas. A quantidade de cursos existentes em fins dos anos 1970 praticamente dobrou (Janasi 2012). O que mudou? Nesse contexto, aparentemente favorável, insere-se a aprovação das DCNGEG pelo CNE. Que fatores determinaram tal reversão de tendência?

\section{Currículo Mínimo e Diretrizes do Fórum Nacional de Cursos de Geologia (FNCG)}

Por iniciativa do Instituto de Geociências da UFBA, realizou-se na cidade de Salvador, Bahia, entre 30 de maio e 1 de junho de 2001, o I Seminário Nacional sobre Cursos de Graduação em Geologia, com a participação de coordenadores de curso e representantes de 16 (dezesseis) das 19 (dezenove) universidades brasileiras que oferecem o cur- 


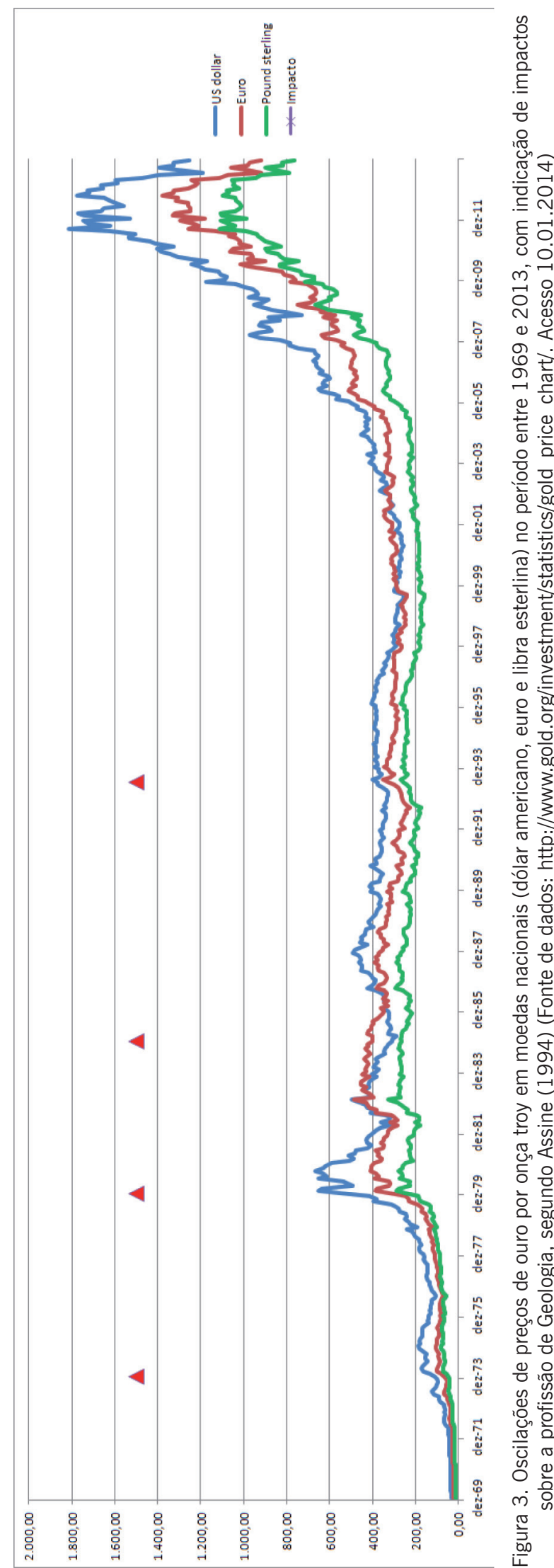

so. O documento sobre o qual os debates se concentraram havia sido elaborado em 1999 pela Sub-Comissão de Especialistas de Ensino de Geologia, formada por três membros da "Comissão de Especialistas de Ensino de Geologia e Oceanografia” designada pelo MEC (Santos et al. 1999). Ao final do encontro, foi aprovado um documento intitulado Sugestões de Alteração da Proposta de Diretrizes Curriculares para os Cursos de Graduação em Geologia e Engenharia Geológica (Mesquita e Carneiro 2001). No ano seguinte, em Campinas, SP, o Instituto de Geociências da Unicamp acolheu, no mês de abril, o II Seminário Nacional sobre Cursos de Graduação em Geologia, que teve participação ainda mais expressiva: estiveram presentes 18 (dezoito) das 19 (dezenove) universidades brasileiras que oferecem o curso. A criação do FNCG fora uma decisão unânime do evento, reforçando-se a pressão para que o MEC acolhesse a contribuição da comunidade acerca das DCNs.

O FNCG passou a realizar encontros periódicos destinados a produzir diagnósticos, promover troca de experiências e conhecimentos, estimular debates e produzir recomendações a respeito dos projetos pedagógicos de cursos. Mais recentemente, com a significativa expansão de cursos de graduação na área, o FNCG passou a destacar, nas reuniões e debates, diversos tópicos relacionados ao conteúdo curricular, práticas de ensino de campo das escolas de geologia, expansão e melhoria da infraestrutura dos cursos tradicionais, bem como o incentivo à inclusão dos novos cursos como integrantes do Fórum. Duas metas foram estabelecidas como prioritárias pelo Fórum: a aprovação das Diretrizes Curriculares pelo governo e a preservação do Centro de Geologia Eschwege (CGE). O CGE nos anos 1980 havia sido institucionalizado graças a sua vinculação à UFMG, mas ao longo dos anos 2000, continuou sob ameaça de interrupção das atividades.

Uma versão completa da proposta aprovada pelo FNCG das Diretrizes Curriculares para os Cursos de Graduação em Geologia e Engenharia Geológica foi publicada na revista Terre Didatica (Nummer et al. 2005), tendo sido mais tarde ligeiramente modificada e aprimorada (Fantinel et al. 2008). Na falta de uma orientação oficial do MEC, os textos tornaram-se uma orientação geral para todos os cursos existentes 
Relação formados/vagas no ano de ingresso: Geologia

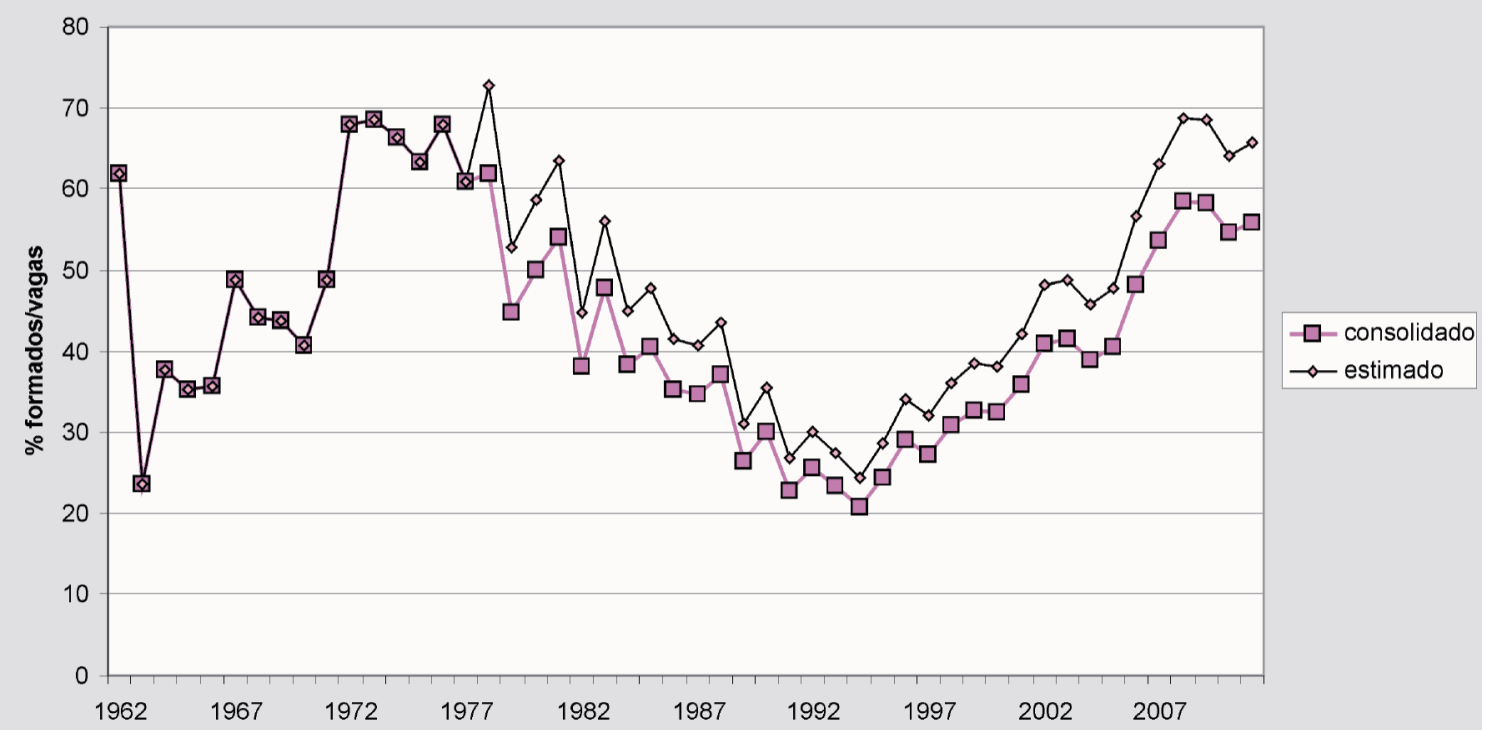

Figura 4. Relação formados/vagas no curso de Geologia USP no ano de ingresso, período de 1962 a 2012 (Fonte: Janasi 2012)

e para aqueles que vieram sendo posteriomente criados no País.

A estrutura geral dos documentos de Diretrizes Curriculares de Geologia elaborados pelo Fórum é composta pelos seguintes itens: (1) Perfil desejado do egresso; (2) Competências e habilidades do egresso; (3) Conteúdo curricular, dividido nas categorias: (a) conteúdo básico; (b) conteúdo para formação geológica específica; (c) conteúdos temáticos; (d) conteúdo complementar; (4) Trabalho de conclusão de curso; (5) Duração do curso; (6) Planejamento da estrutura curricular; (7) Atividades complementares; e (8) Trabalho de Campo.

Durante o $3^{\circ}$ Encontro do FNCG, realizado em 2003 na cidade de Belém, nas dependências do Instituto de Geociências da UFPA (Carneiro e Assis 2005), foram aprovadas, dentre outras, as seguintes medidas: (a) elaborar um texto geral para delimitar quais são as competências do geólogo e ampliar a proposta de Diretrizes Curriculares; (b) atualizar a pesquisa realizada pelo MEC e SBG nos anos 1980 (Amaral et al. 1981). No $4^{\circ}$ Encontro, realizado em Araxá (2004), o tema dos trabalhos de campo foi discutido amplamente, inexistindo unanimidade quanto às horas que deveriam ser computadas por dia de trabalho no campo (6, 8 ou 10 horas?); a decisão foi deixar a definição a cargo de cada IES, que estabeleceria sua norma interna. Aprovou-se a elaboração de texto a respeito da importância do campo na formação do geólogo.

Importante deliberação do $7^{\circ}$ Encontro do
FNCG, realizado em 2007, corrige um equívoco contido na versão de 2005 das DCNs, devido a se adotar como unidade a hora-aula e não uma hora de sessenta minutos para definir a carga horária mínima do curso (Fantinel et al. 2008). Em cursos do período diurno, uma hora-aula perfaz 50 minutos, ao passo que, para cursos do período noturno, uma hora-aula perfaz $40 \mathrm{minu}$ tos. Desse modo, cursos de 3.600 horas-aula de quarenta minutos seriam obviamente mais curtos que cursos de 3.600 horas de sessenta minutos. Ao mesmo tempo em que o Fórum referendou o documento das DCNs, estabeleceu-se que a duração mínima dos cursos devesse ser de cinco anos. O Trabalho de Campo, considerado de máxima relevância para a formação do geólogo, foi igualmente modificado de modo a estabelecer-se uma carga horária mínima de atividades de campo, que "deve ser planejada e incluída na programação dos cursos, e pode estar contida, ou não, na carga horária de diferentes disciplinas" (Nummer et al. 2005, Fantinel et al. 2008). O nível mínimo requerido é de $20 \%$ do total do curso, perfazendo, por exemplo, um total de 720 horas efetivas de trabalhos de campo para um curso de duração mínima de 3.600 horas. Os dados existentes ${ }^{1}$ indicam que a ampla maioria dos cursos possui duração superior a 3.600 horas.

Na versão precedente de Currículo Mínimo as

1 Infelizmente não se dispõe de dados consistentes de alguns cursos criados em instituições particulares nos últimos anos. 
atividades de Geologia de Campo também haviam sido extremamente valorizadas para a formação do geólogo, tendo sido estabelecida uma carga horária mínima durante todo o curso de 800 horas (SBGeo 1983, p.28), para cursos com carga horária mínima de 3.600 horas. A proposição do Fórum, como se pode ver, pouco altera esse quadro.

\section{As diretrizes curriculares (DCNGEG)}

A implementação das DCNGEG implica o desafio de formar geólogos/as e engenheiros/as geólogos/as com competência técnica e política, como sujeitos sociais dotados de conhecimento, raciocínio, percepção e sensibilidade para as questões da vida, da ciência, da técnica e da sociedade, capacitando-os a trabalhar em qualquer área de aplicação das Ciências Geológicas, e que possuam: (a) interesse e capacidade para o trabalho de campo; (b) visão abrangente das Geociências e de suas interações com ciências correlatas; (c) pleno domínio da linguagem técnica geológica, aliada à capacidade de adequação desta linguagem à comunicação com outros profissionais e com a Sociedade; (d) conhecimento de ciências exatas que permita abordagens quantitativas das informações geológicas; (e) familiaridade com métodos e técnicas de informática, especialmente no tocante ao geoprocessamento. A proposta aprovada pelo CNE, homologada no dia 3 de julho de 2014 pelo MEC, privilegia a formação aprofundada, que incluirá capacidade de abordar e resolver problemas geológicos com competência, aliando uma sólida base teórica a um treinamento prático e intensivo. Espera-se que o/a egresso/a dos cursos possua atitude ética, empreendedora, autônoma, crítica, criativa e seja dotado de atuação propositiva, na busca de soluções de questões de interesse da Sociedade (Fantinel et. al. 2008). É prevista a oferta de conteúdo complementar ao longo dos cursos, de caráter optativo, que buscará oferecer ao aluno, a critério de cada $\mathrm{IES}^{2}$, conteúdos de Ciências Humanas, como por exemplo, tais como Economia, Filosofia da Ciência, Gestão, Administração e Comunicação.

Duas outras inovações foram introduzidas nas DCNGEG: a existência de um Trabalho de Conclusão de Curso para integralização do curso de Geologia ou Engenharia Geológica, que deverá versar sobre temas de conteúdo geológico. A carga horária prevista para os cursos deverá permitir que o aluno participe de atividades extra-curriculares,

2 Instituição de Ensino Superior. como projetos de iniciação científica, projetos de pesquisa, monitoria didática ou estágios em áreas relacionadas à Geologia ou suas interfaces. Cada IES deverá estimular o aluno, preferencialmente no último ano do Curso, a desenvolver atividades de estágios em instituições externas à Universidade, sob a supervisão de um professor, apresentando um relatório técnico de suas atividades.

\section{Vertentes de Formação e Competências}

No relatório aprovado pelo CNE consta importante distinção a respeito das linhas que podem ser adotadas nos cursos de Engenharia Geológica, que poderão ser concebidos segundo duas linhas distintas:

\begin{abstract}
A primeira, como vertente da formação na área da Geologia, descrita no presente Parecer, e a segunda, como vertente da formação em outras modalidades de Engenharia. (...) a formação em Engenharia Geológica poderá seguir as presentes Diretrizes ou as Diretrizes gerais para os cursos de Engenharia, estabelecidas pela Resolução CNE/CES n ${ }^{\circ} 11$, de 11 de março de 2002. De toda forma, (...) as formações acadêmicas resultantes nos dois casos são altamente compatíveis.
\end{abstract}

O documento reconhece, para o momento atual, dentre outras, as seguintes competências do geólogo ou engenheiro geólogo:

1. Realizar mapeamento geológico e exercer as demais competências discriminadas na Lei $\mathrm{n}^{\circ}$ 4.076, de 23 de junho de 1962, tais como: trabalhos topográficos e geodésicos, levantamentos geoquímicos e geofísicos, estudos relativos às ciências da Terra, trabalhos de prospecção e pesquisa para a cubagem de jazidas e determinação de seu valor econômico,

2. Planejar, executar, gerenciar, avaliar e fiscalizar projetos, serviços e ou pesquisas científicas básicas ou aplicadas que visem ao conhecimento e à utilização racional dos recursos naturais e do ambiente.

3. Pesquisar e otimizar o aproveitamento tecnológico dos recursos minerais e energéticos sob o enfoque de mínimo impacto ambiental.

4. Pesquisar novas alternativas de exploração, conservação e gerenciamento de recursos hídricos

5. Fornecer as bases para o planejamento da 
ocupação urbana e para a previsão e prevenção de riscos de acidentes por desastres naturais e aqueles provocados pelo homem.

6. Desenvolver métodos de ensino e pesquisa das Geociências voltados tanto para a melhoria do desempenho profissional como para a ampliação do conhecimento em geral.

7. Desenvolver e aplicar métodos e técnicas direcionadas à gestão ambiental.

8. Atuar em áreas de interface, como a Tecnologia Mineral, Ciências do Ambiente e Ciências do Solo.

\section{Novos desafios, uma novidade...}

Preservando-se o espírito da proposta original da SBGeo para o Currículo Mínimo, os documentos do Fórum e as DCNGEG preveem que os cursos superiores da área devam garantir "uma formação polivalente voltada para as necessidades do País na área de Geologia" (SBGeo 1983, p.19). Janasi (2012) assinala que as escolhas do graduando devem ser feitas com certa liberdade,

Dentro de suas vocações e possibilidades, as escolas devem oferecer um leque de opções, deixando a escolha de uma formação direcionada por conta do aluno, vista das flutuações dos interesses pessoais e do mercado de trabalho ao longo da futura vida profissional (Janasi 2012).

$\mathrm{Na}$ decisão do CNE é previsto ainda que "a emergência futura de novas alternativas de formação poderá ensejar a extensão das presentes Diretrizes" (Curi 2012). O relator qualifica as atividades promovidas pela SBGeo e o Fórum Nacional, para propor currículos de referência, como:

“(...) importantes contribuições à qualidade da formação na área, mas não como imposição de modelos de adoção obrigatória, ficando assegurada ampla autonomia às IES para formular projetos pedagógicos que, seguindo as presentes Diretrizes Curriculares, expressem a diversificação desejável que é a essência da concepção de Diretrizes Curriculares em oposição aos extintos Currículos Mínimos" (Curi 2012).

É importante lembrar que o estágio supervisionado havia sido previsto nos documentos de proposta de DCNs como um conjunto de atividades optativas, definidas pelas IES (Santos et al. 1999,
Nummer et al. 2005, Fantinel et al. 2008). Com a decisão do CNE o estágio supervisionado tornou-se obrigatório, devendo proporcionar ao aluno:

“(...) conhecimentos e experiências profissionais, ao permitir a interação da escola com a empresa. (...) A carga horária mínima sugerida é de 120 horas a 160 horas, podendo ser expandida no recesso de aulas escolares" (Curi 2012).

Em síntese, qualquer reformulação curricular de cursos de geologia deve atentar para o fato de que o currículo constitui uma construção coletiva, que deve envolver o maior número possível de atores/ participantes. Um bom currículo de curso de graduação é aquele que permite ao aluno: (a) adquirir competências cognitivas complexas; (b) dispor de autonomia intelectual, criatividade e capacidade de resolução de problemas; (c) construir base sólida que o habilite a ter flexibilidade em futuras situações que requeiram discernimento, capacidade de análise e prospecção da conjuntura, para o correto equacionamento de oportunidades e desafios. Além disso, o currículo é um projeto cultural que, como tal, requer esforços conjugados dos docentes, que precisam refletir sobre suas funções; compreender e dominar a teoria; construir firme experiência própria, além de dominar os recursos didático-pedagógicos (Menegat 2005); isso requer atualização de conceitos e aperfeiçoamento pedagógico, e ao mesmo tempo exige trabalho em equipe dos professores e alunos, sob supervisão pedagógica eficiente.

\section{Visão sistêmica, histórica e integrada com base na realidade externa à sala de aula}

$\mathrm{Na}$ moderna concepção das Geociências, a abordagem proporcionada pela Ciência do Sistema Terra explora as características essenciais, a configuração atual e a história evolutiva de cada uma das esferas terrestres, com foco na interação entre elas (Gonçalves e Carneiro 2002), e estabelece relações entre a sociedade humana e a natureza (Carneiro e Gonçalves 2010, 2013). Os pesquisadores e profissionais da área reúnem vasto acervo de dados e conhecimentos específicos locais e regionais sobre a Terra, e ao mesmo tempo são capazes de integrar o saber para compor modelos de funcionamento do planeta como um todo. O ensino-aprendizagem pode despertar nos alunos uma reflexão sobre as relações do homem e o planeta (Carneiro et al. 2005), que deveriam ser estendidas para os níveis 
escolares da educação básica (Carneiro et al. 2004).

Os trabalhos de campo e as atividades externas à sala de aula, ao serem cada vez mais valorizados (Carneiro et al. 2008), estimulam o desenvolvimento de raciocínios tais como aqueles destacados por Paschoale (1984), que contribuem para o melhor entendimento da natureza e as limitações do pensamento humano e, ademais, favorecem a autocompreensão (Marques e Praia 2007). Assim, as Instituições de Ensino Superior (IES) precisam de apoio de modo a contar com recursos financeiros e infraestrutura que as habilitem a desenvolver trabalhos de campo, obedecendo a métodos apropriados de ensino e de orientação docente eficaz aos alunos.

Ainda que a complexidade de interpretação dos processos do ambiente natural ofereça grande dificuldade aos alunos, os futuros geólogos e engenheiros geólogos precisam, não obstante, construir uma perspectiva social mais sólida e bem fundamentada em Geociências. Esse aspecto se acha devidamente contemplado nas DCNGEG.

Em geral os cursos superiores brasileiros têm reservado o último ano dos cursos para oferecer disciplinas profissionalizantes. Diversos autores, como Vaz (2013), revelam preocupação com a carga excessiva de conteúdos geocientíficos contidos nas "disciplinas instrumentais", cujo volume pode dificultar abordagens mais completas de conteúdos inerentes às disciplinas "profissionalizantes". Se por um lado aquelas ajudam a formar o raciocínio do geólogo e lhe fornecem adequado instrumental de trabalho, estas últimas propiciam conexão direta com aquilo que o geólogo efetivamente encontrará no ambiente das empresas, órgãos de governo e corporações. Vaz (2013) recomenda que a imersão em conteúdos profissionalizantes devesse acontecer nos dois últimos anos do curso, o que implica abrir mais tempo livre na carga horária. É, pois, um grande desafio atingir um equilíbrio adequado entre a quantidade de horas a serem dispendidas ao longo do curso para disciplinas profissionalizantes, vis-a-vis com as disciplinas instrumentais.

\section{0 cenário internacional e consequências das dcngeg}

Examinando-se o tema em escala mais ampla, as Diretrizes Curriculares Nacionais para cursos de graduação em Geologia e Engenharia Geológica (DCNGEG) são estabelecidas em um cenário internacional bastante competitivo, quando, por exemplo, a União Europeia reconhece "a necessidade de investir em capital humano, superar as limitações quanto ao uso das tecnologias, desenvolver uma política de empregos e lutar por uma Europa do conhecimento, competitiva, dinâmica e eficaz" (Tato 2005, apud Silva 2013). O Espaço Europeu de Educação Superior (EEES) foi criado para fazer frente a descompasso entre "a formação superior oferecida pelas universidades e as necessidades e dilemas econômicos e sociais". Em paralelo, estabelecem-se políticas para correção de desvios, necessárias para realinhar ganhos empresariais. Desencadeia-se "um modelo de política educacional subordinada ao modelo econômico, que tenta aproximar universidade e a escola das empresas" (Silva 2013).

(...) de uns tempos para cá, nos anos noventa, tornou-se um costume político desqualificar a formação universitária e alegar descompasso entre a formação inicial e as necessidades profissionais, para justificar a substituição ou supressão de saberes e conteúdos com vistas a redirecionar o perfil profissional, colocando o estudante em condições de seguir aprendendo. Ao mesmo tempo, a formação superior tornou-se exigência basilar para estar em condições de disputar um posto no mercado de trabalho (Silva 2012).

O EEES, na qualidade de uma articulação política liderada por chefes de Estado e ministros de Educação dos Estados-Membros (Silva 2013), espera que a universidade se organize "segundo modelos flexíveis, eficientes, dinâmicos, criativos, inovadores" e que se crie uma "cultura de competitividade para produzir resultados efetivos e quantificáveis". Silva (2013) acentua o antagonismo existente entre tal premissa, que circula no ambiente das decisões políticas e econômicas, e outra, conduzida pelos movimentos sociais e populares que defendem a universidade e a escola como bens públicos, "e a formação como um direito de todos e um dever do Estado".

Muito embora no contexto brasileiro tais questões não tenham sido colocadas com tanta evidência e com a mesma clareza, parecem ter sido assimiladas preocupações semelhantes, no sentido de estimular os indivíduos a aprender a aprender, assumir a responsabilidade pela própria aprendizagem (Saviani 2002), agir de modo ativo para procurar adquirir conhecimentos e desenvolver suas competências (COM678 2001, Silva 2013).

O cenário internacional, portanto, é de que 
os Estados nacionais passam a atribuir enorme valor para a formação superior. Longe de supor que as DCNGEG ajudariam cursos de qualidade mediana a se manter, o entendimento que ora se faz das DCNs é a de que elas aprimoram o ensino e a formação profissional de maneira geral, sob a premissa de que a formação superior é direito de qualquer cidadão e dever do Estado. Dentre as consequências imediatas e de longo prazo incluem-se: (a) a organização de novos currículos; (b) a eventual reformulação de currículos atuais; (c) o diálogo e interação com os órgãos que regulamentam exercício profissional, como o sistema CREA-CONFEA, e (d) a própria avaliação periódica dos cursos.

\section{Conclusões}

Nos anos 2000, comemorou-se meio século de existência dos primeiros cursos superiores brasileiros de graduação em Geologia. Criado em 2002, o Fórum Nacional de Cursos de Geologia concentrou esforços ao longo da década para realizar duas metas centrais: a aprovação das Diretrizes Curriculares e a preservação e manutenção do Centro de Geologia Eschwege. Excetuando-se a segunda, que nos anos 1980 era objeto de iniciativas para institucionalizar o CGE, por meio de vinculação à UFMG, as ações do Grupo de Ensino de Geologia (GEG) ajudaram a construir a base legal do Currículo Mínimo dos cursos. Pode-se afirmar que, justamente devido ao fato de serem compartilhadas até hoje no âmbito da comunidade geológica nacional, as ideias dominantes daquela época mantiveram-se e ajudaram a compor as atividades do Fórum desde sua criação. Podemos vislumbrar certa continuidade, em outro nível estratégico, das iniciativas de modificação curricular introduzidas pelo GEG.

A forma como foram aprovadas pelo CNE e MEC as Diretrizes Curriculares Nacionais para cursos de graduação em Geologia e Engenharia Geológica representa reconhecimento das ações ordenadas do Fórum. Os coordenadores de cursos, em várias oportunidades, poderiam ter alterado a proposta original, mas decidiram não o fazer, de modo a assegurar certa perenidade para o que havia sido proposto. O CNE parece ter reconhecido e valorizado esse aspecto. As DCNs garantem suporte à flexibilidade responsável dos currículos, sempre apoiada por ferramentas didáticas como os trabalhos de campo e atividades correlatas. Uma dificuldade que poderá persistir por muito tempo refere-se à desejável busca de um equilíbrio entre a quantidade de horas de disciplinas profissionalizantes e de disciplinas instrumentais ao longo do curso.

As DCNGEG surgiram em época na qual emerge em diversos países uma extrema valorização de iniciativas de melhoria educacional, e se reconhece a influência potencial da sociedade do conhecimento e da informação em um contexto competitivo e dinâmico das diferentes sociedades. A orientação geral é cada vez mais necessária para que se formem geólogos/as e engenheiros/as geólogos/as com competência técnica e política, capazes de usar a capacitação, o conhecimento, o raciocínio, a percepção e a sensibilidade para trabalhar em qualquer área de aplicação das Ciências Geológicas.

A liberdade para o estudante buscar desenvolver seu autoaprendizado ativo e assimilar uma atitude ética, empreendedora, autônoma, crítica, criativa, ao mesmo tempo em que adquire um certo leque de competências, parece ser a recomendação central tanto do modelo preconizado pelo CNE como das propostas defendidas pelo FNCG. Tal perspectiva amplia, em certo sentido, o escopo da formação profissional em Geologia rumo a uma formação cidadã mais consciente e aprofundada.

Talvez essa mudança no tipo de concepção vigente seja a mais importante alteração que se poderá imprimir nos cursos universitários.

\section{Referências Bibliográficas}

Almeida F.F.M.de 2004. O Centro de Pesquisas Geocronológicas da USP e a comprovação da Teoria da Deriva dos Continentes. São Paulo, 8.12.2004. (Discurso de agradecimento a homenagem feita pelo Inst. Geoc. USP, inédito).

Amaral I.A.do. 2013. Raízes da mudança curricular ocorrida em 1973 na USP. In: Interfaces Geociências e Ensino: 40 anos de experiências (19732013), Campinas, SP, 23 e 24 de agosto de 2013. (Apres. Oral).

Amaral I.A.do. 2014. Raízes da mudança curricular ocorrida em 1973 na USP. Terre Didatica, 10(3):161-170. URL: http:// www.ige.unicamp. $\mathrm{br} /$ terraedidatica/.

Anguita F. 1996. Geología y ciencias de la Tierra: etimología y un poco de historia. Revista de Enseñanza de las Ciencias de la Tierra, 4(3):177-180.

Assine M.L. 1994. Repensando os cursos de graduação em Geologia. Cadernos IG-Unicamp, 4(1):34-65.

Azevedo R.L.M.de, Terra G.J.S.. 2008. A busca do petróleo, o papel da Petrobras e o ensino da Geologia no Brasil B. Geoci. PETROBRAS, 16(2):373-420.

Barroso E.V. 2008. SBG/Sede - comemoração aos 50 anos 
do curso e graduação em Geologia da UFRJ. Email de 27 Nov 2008 da Sociedade Brasileira de Geologia SBGeo sbgeo60@gmail.com a todos os associados.

Brasil. Ministério da Educação. 1996. Lei n. 9.394, 20 de dezembro de 1996. Estabelece as diretrizes e bases da educação nacional. Brasília (DF), Diário Oficial da República Federativa do Brasil, 23 dez. 1996; Seção 1, p. 833-841.

Brasil. Ministério da Educação. Conselho Nacional de Educação. Câmara de Educação Superior. 2012. Resolução CNE/CES n. 387/2012, de 7 novembro de 2012. Institui as diretrizes curriculares nacionais para o curso de graduação em Geologia e em Engenharia Geológica, bacharelados. Brasília (DF), 7 nov. 2012. (Relator Luiz Roberto Liza Curi, Proc. No: 23001.000110/2007-41).

Carneiro C.D.R. 2013. Fórum Nacional de Cursos de Geologia (FNCG). In: Interfaces Geociências e Ensino: 40 anos de experiências (1973-2013), Campinas, SP, 23 e 24 de agosto de 2013. (Apres. Oral).

Carneiro C.D.R., Assis J.F.P. 2005. Relato Final do II Encontro do Fórum Nacional de Cursos de Geologia. Belém, maio de 2003. Terre Didatica, 1(1):74-83. URL: http://www.ige.unicamp.br/terraedidatica/v1n1/t_didatica_2005_v01n01_p074083 carneiro assis.pdf. Acesso 21.03.2013.

Carneiro C.D.R., Gonçalves P.W. 2010. Earth System Science for undergraduate Geology and Geography courses, Campinas, Brazil. Terrae, 7(1):29-40. URL: http://www.ige.unicamp.br/terrae/. Acesso 14.03.2011.

Carneiro C.D.R., Gonçalves P.W., Negrão O.B.M., Cunha C.A.L. 2005. Ciência do Sistema Terra e o entendimento da "máquina" planetária em que vivemos. Belo Horizonte, Geonomos, 13(1):11-18.

Carneiro C.D.R., Gonçalves P.W., Negrão O.B.M., Cunha C.A.L. 2008. Docência e trabalhos de campo nas disciplinas Ciência do Sistema Terra I e II da UNICAMP. Rev. Bras. Geoc., 38(1):130142. (março 2008). URL: http://ojs.c3sl.ufpr.br/ ojs2/index.php/rbg/article/view/9816/8972. Acesso 14.03 .2011 .

Carneiro C.D.R., Toledo M.C.M.de, Almeida F.F.M.de. 2004. Dez motivos para a inclusão de temas de Geologia na Educação Básica. Rev. Bras. Geoc. 34(4):553-560.

Cervato C., Frodeman R. 2012. The significance of geologic time: cultural, educational, and economic frameworks. The Geol. Soc. Am., Special Paper, n. 486, p.19-27. URL: http://www.ige. unicamp.br/terraedidatica/v10 1/6.html. Acesso 25.10.2014.

COM590 Final. Comissão das Comunidades Europeias. 1995. White Paper on Education and Training - Teaching and Learning. Towards the Learning Society. COM590 Final, Bruxelas, nov. 1995.
COM(95) 590. URL: http://europa.eu/documents/comm/white_papers/pdf/com95_590_ en.pdf. Acesso 13.12.2013.

COM678. Comissão das Comunidades Europeias. 2001. Tornar o espaço europeu de aprendizagem ao longo da vida uma realidade. COM 678 final. Bruxelas, 2001.

Cunha C.A.L.S. 2013. Movimento de consolidação nacional de novas bases para o Ensino de Geociências. In: Interfaces Geociências e Ensino: 40 anos de experiências (1973-2013). (Apres. Oral).

Cunha C.A.L.S. 2014. Movimento de consolidação nacional de novas bases para o Ensino de Geociências. Terrce Didatica, 10(2):xx-yy. http://www. ige.unicamp.br/terraedidatica/.

Curi L.R.L. 2012. Diretrizes curriculares nacionais para o curso de graduação em Geologia e em Engenharia Geológica, bacharelados. Brasília (DF), CNE. (Rel. à Câmara de Educação Superior do Conselho Nacional de Educação, Proc. No: 23001.000110/200741).

Fantinel L. et al. 2008. Diretrizes curriculares para os cursos de graduação em Geologia e Engenharia Geológica. Terree Didatica, 4(1):85-89. http://www. ige.unicamp.br/terraedidatica/ .

Gonçalves P.W., Carneiro C.D.R. 2002. Global Science Literacy: from Geology teaching to Earth System Science teaching. In: Mayer V.J. ed. 2002. Implementing Global Science Literacy. Columbus, Ohio: Earth Systems Education Program / The Ohio State Univ. v. 2, chapter 14, p. 203-220.

Grupo de Ensino de Geologia. 1979. Ata da primeira reunião do Grupo de Ensino de Geologia. São Paulo. (doc. inédito).

Hooke R.L.B. 2000. On the history of humans as geomorphic agents. Geology; 28(9):843-846. URL: http://geology.geoscienceworld.org/cgi/content/ full/28/9/843\#F04. Acesso 01.10.2009.

Janasi V.A. 2012. O Ensino de Graduação em Geociências no Brasil: Avaliação e Perspectivas (por solicitação da SBG, SBGf, SBGq). São Paulo: IGc-USP. (Apres. Powerpoint).

Marques L., Praia J. 2009. Educação em Ciência: actividades exteriores à sala de aula. Terre Didatica, 5(1):10-26. URL: http://www.ige.unicamp.br/ terraedidatica/. Acesso 20.02.2014.

Menegat R. 2005. Reformulação curricular do curso de Geologia. Porto Alegre: IG-UFRGS. (Apres. Powerpoint; Doc. base: Texto 13: Diretrizes curriculares do ensino fundamental e médio. Conselho Estadual de Educação do Rio Grande do Sul. Parecer 323/99 CEE/RS. Proc. CEED n. 408/27.00/98.5).

Menegat R. 2008. A invenção da terra moderna por René Descartes: a difícil revolução científica das esferas terrestres. B. Geoci. PETROBRAS, 16(2):421-453. 
Mesquita F.J.G.de, Carneiro C.D.R. 2001 Sugestões de Alteração da Proposta de Diretrizes Curriculares para os Cursos de Graduação em Geologia e Engenharia Geológica. Salvador: UFBA. (inédito).

Ministério da Educação. Conselho Nacional de Educação. (Curi L.R.L., Relator). 2012. Proposta de Diretrizes Curriculares Nacionais para o curso de graduação em Geologia e em Engenharia Geológica, bacharelados. Proc. No: 23001.000110/2007-41. Parecer CNE/ CES No: 387/2012. Aprov. em: 7/11/2012.

Negrão O.B.M. 2013. Curso de Especialização para professores de Geociências. In: Interfaces Geociências e Ensino: 40 anos de experiências (1973-2013), Campinas, SP, 23 e 24 de agosto de 2013. (Apres. Oral).

Negrão O.B.M. 2014. Curso de Especialização para professores de Geociências. Terrce Didatica, 10(3):178-190. http://www.ige.unicamp.br/terraedidatica/V10 3/3-108.html

Nummer A.R. et al. 2005. Diretrizes Curriculares para os Cursos de Graduação em Geologia e Engenharia Geológica. Terre Didatica, 1(1):64-69. URL: http://www.ige.unicamp.br/terraedidatica/ v1n1/t_didatica_2005_v01n01_p064-069_nummer et al.pdf.

Orion N. 2001. A Educação em Ciências da Terra: da teoria à prática. Implementação de novas estratégias de ensino em diferentes ambientes de aprendizagem. In: L. Marques, J. Praia. coords. 2001. Geociências nos currículos básico e secundário. Aveiro: Univ. Aveiro. p.93-114.

Pablos J.L. 2004. Complejidad y Dualidad en el Sistema Terra. Rev. de la Enseñanza de las Ciencias de la Tierra, 12(3):243-247. URL: http://www.raco.cat/ index.php/ECT/article/download/89002/133305. Acesso 28.02.2013.

Paschoale C. 1984. Alice no país da Geologia... e o que ela encontrou lá. In: Congr. Bras. Geol., 33, Rio de Janeiro, 1984. Anais... Rio de Janeiro, SBG. v. 11. p. $5242-5249$.

Peter A., Hodder W. 1997. The transformation of Geology to Earth Sciences: an example of the appropriation of technology by science. Int. J. Sci. Educ. 19(5):553-563. URL: http://www.tandfonline.com/doi/abs/10.1080/0950069970190504. Acesso 12.02.2013.

Potapova M.S. 2008. Geologia como uma ciência histórica da natureza. Terrae Didatica, 3(1):86-90. [Trad. de: Potapova M.S 1968. Geology as an historical science of nature. In: Interaction of the science in the study of the Earth. Moscow: Progress, p.117-126]. URL: http://www.ige.unicamp.br/ terraedidatica/v3/v3 a7.html. Acesso 27.02.2014.

Santos M.I.F.dos, Gomes N.S., Landim P.M.B., Vieira P.J.C., Fuck R.A. 1999. Diretrizes Curriculares para os Cursos de Graduação em Geologia e Engenharia Geológica. Brasília: Ministério da Educação, Secr. Educ. Superior. Coord. Comissões de Especialistas de Ensino.

Saviani D. 2002. O trabalho como princípio educativo frente às novas tecnologias. In: Ferreti C.J. et al. (orgs.). Novas tecnologias, trabalho e educação: um debate multidisciplinar. 8 ed. Petrópolis, Vozes. p. 151-168.

Silva M.A.da. 2012. Educação e formação docente no ensino superior da União Europeia. RBPAE, 28(3):607-628. URL: seer.dev.ufrgs.br/index. $\mathrm{php} / \mathrm{rbpae} / \mathrm{article} / \mathrm{download} / 39829 / 25378$. Acesso 27.02.2014.

Silva M.A.da. 2013. A formação docente na visão dos ministros de educação e chefes de estado da UE. Goiânia, Inter-Ação, 38(2):407-427. DOI 10.5216/ ia.v38i2.26132. Acesso 17.12.2013.

Simpson G.G. 1963. Historical science. In: Albritton Jr. C.C. ed. 1963. The fabric of geology. Stanford : Freeman, Cooper \& Co. p.24-48.

Sociedade Brasileira de Geologia (SBG). 1982a. Simpósio Nacional sobre o Ensino de Geologia no Brasil 1. 1981 Belo Horizonte. Documento Final... São Paulo: Sociedade Brasileira de Geologia. 155p.

Sociedade Brasileira de Geologia (SBG). 1983. Simpósio Nacional sobre o Ensino de Geologia no Brasil. Currículo Mínimo, 2. 1982, Salvador. Documento Final... São Paulo: SBG. 73p.

Sociedade Brasileira de Geologia (SBG). 1984. A formação do geólogo nas universidades brasileiras: um retrato de duas décadas. São Paulo: SBG.

Tato M.S. 2005. Política educativa europea. Revista de Educación, (337):251-278.

Vaz L.F. 2013. Currículo profissionalizante para cursos de Geologia. In: congr. Bras. Geol. Eng. e Ambiental, 14, Rio de Janeiro, 2013. Anais..., Rio de Janeiro, ABGE. (II SEGEA, II Simp. Ens. Geol. Eng. Amb.). 